\title{
"A place to be safe, feel at home and get better": Including the experiential knowledge of potential users in the design of the first wet service in Montreal, Canada
}

\section{ROSSIO MOTTA OCHOA}

University of Quebec in Montreal: Universite du Quebec a Montreal https://orcid.org/0000-0003-4083-

7414

\section{Natalia Incio-Serra}

McGill University Faculty of Education

Hélène Poliquin

Institut national de sante publique du Quebec

Sue-Ann MacDonald

Université de Montréal: Universite de Montreal

Christophe Huỳnhe

Université de Montréal: Universite de Montreal

Philippe-Benoit Côté

Universite du Quebec a Montreal

Jean-Sébastien Fallu

Université de Montréal: Universite de Montreal

Jorge Flores-Aranda ( $\square$ flores-aranda.jorge@uqam.ca )

Université de Montréal: Universite de Montreal https://orcid.org/0000-0002-4392-2270

Research

Keywords: wet shelters, drop-in centers, transitory housing, poverty, stigmatization, police harassment

Posted Date: October 5th, 2021

DOl: https://doi.org/10.21203/rs.3.rs-944738/v1

License: (9) (1) This work is licensed under a Creative Commons Attribution 4.0 International License.

Read Full License 


\section{Introduction}

The harmful use of alcohol is a leading global risk factor for human health, and was the seventh cause of premature death and disability in 2016 (1). Worldwide, around 3 million deaths and 132.6 million disability-adjusted years are attributable to alcohol consumption (2). Harmful use of alcohol is also linked to noncommunicative diseases, being the attributable cause of 1.2 million deaths from digestive and cardiovascular disease, and 0.4 million deaths from cancer. Moreover, 107 million people are estimated to have alcohol use disorders worldwide (3). Noticeably, harmful use of alcohol is not uniformly distributed. Some populations, such as people who experience homelessness, are more vulnerable to the detrimental effects of alcohol use (4)(5). For example, the prevalence of alcohol dependence amongst people who experience homelessness in high income countries is around 38\%, which is almost 10 times higher than among the general population (6).

Additionally, among persons who experience homelessness, there is a higher prevalence of numerous physical conditions directly related to alcohol dependence, including chronic inflammation of the digestive system, liver inflammation and cirrhosis, pancreatitis, hypertension, cardiomyopathy and coronary heart disease, alcohol-related seizures, and damage to the central nervous system (7)(8). Moreover, people experiencing homelessness suffer from elevated rates of mental illness that often co-occur with alcohol use (9). They are also more vulnerable to physical injures that result from falls, traffic accidents and assaults (10). Furthermore, people who experience homelessness are exposed to the harsh living conditions of the streets (e.g., extreme weather, robbery, harassment, police profiling and discrimination), which contribute to the deterioration of their health (11)(12). Although it is reported that they overutilize emergency services for urgent medical care (13)(14), they also experience difficulties accessing primary and specialized health services, mental health services and housing (6)(15)(16). Among the access barriers to public services of people experiencing homelessness, providers' prejudices and judgemental attitudes toward them as well as their distrust of public services have been reported $(17)(18)(19)$. It is notable that the structural vulnerability ${ }^{1}$ of this population due to external forces such as poverty, violence and stigmatization as well as their alcohol dependence and limited access to public services negatively affects their health (21).

However, in the past decades, harm reduction interventions have been developed to address the specific health and social needs of persons who experience alcohol dependence and homelessness. For example, wet services (WSs) include a wide range of arrangements (e.g., wet shelters, drop-in centers, , transitory and permanent housing, elderly care facilities, etc.) offering a safe environment, support and services (e.g., food, activities, primary care, etc.) that allow indoor alcohol use (22). Moreover, Managed Alcohol Programs (MAPs) that provide regulated doses of alcohol in addition to accommodation and services have proven to decrease use of non-beverage alcohol (e.g., hand sanitizer, mouth wash, rubbing alcohol, etc.), reduce alcohol-related harms, stabilize harmful drinking patterns, lessen emergency department visits, limit exposure to police contact, increase housing retention, foster recovery, in addition to improving social relations, wellbeing and quality of life $(23)(24)(25)(26)(27)(28)(29)$. Although there is a growing body of

\footnotetext{
${ }^{1}$ The notion of structural vulnerability as defined by James Quesada and colleagues refers to a positionality that imposes physical/emotional suffering on specific populations and individuals in patterned ways, which is the result of class, cultural, gender/sexual, and/or racialized discrimination (20). In medical anthropology this notion has been used to analyse groups of people that due to their subordinated location in society have higher rates of ill health and limited access to health resources
} 
literature about the impacts of WSs and particularly MAPs on the health, living conditions and wellbeing of people who experience homelessness and alcohol dependence, still little is known about how these services are designed and how participation of potential users can be included in defining such services (30)(31), which could contribute to better tailor them to these people's needs.

To fill this gap in the literature, the present study aims to explore how a group of persons who experience alcohol dependence and homelessness use their experiential knowledge or the information and wisdom gained from lived experience (32) to envision Montreal's first WS. We collected the participants' perspectives to enrich the design of such service and better adapted it to their complex needs. In so doing, we examine their alcohol use, experiences of homelessness, and use of or exclusion from public services as well as ways in which they envision a WS tailored to their specific needs and expectations.

\section{Approach and methods}

This research is a component of a feasibility study to implement the first WS in Montreal, conducted by the Institut universitaire sur le dépendance (IUD). The study combines a communitybased participatory research approach and qualitative methods to better grasp the experiential knowledge of potential users of the WS. Community-based participatory research fosters the participation of community members, people with lived experiences, organizational representatives, local authorities, and other stakeholders as co-researchers (33). Further, it contributes to implementing effective interventions across diverse communities through strategies to redress power differences, foster mutual benefit among community and academic partners, and facilitate reciprocal knowledge translation (34). For this study, IUD researchers worked closely with people who have lived experiences, representatives of community-based organizations that provide services and support to homeless people, Indigenous organizations, health and social services, police services, the City of Montreal and a district where visible forms of homelessness are concentrated. These groups were involved in several steps of the research process, providing feedback for the study design, recruiting research participants, facilitating settings for participant interviews, and discussing and disseminating the study results.

Participants $(\mathrm{N}=34)$ who had profiles similar to potential users of the WS were recruited. The eligibility criteria were 1) not having a fixed address over the last 12 months, 2) being engaged in heavy alcohol drinking ${ }^{2}$ and binge drinking ${ }^{3}$ over the last month, and self-identified as having alcohol dependence, 3) being aged 18 or older, 4) speaking French or English, and 5) having the capacity to understand and consent to participation. To ensure sample diversification (37) age, gender and ethnicity were also considered. Qualitative methods such as semi-structured interviews $(\mathrm{n}=12)$ and focus groups $(\mathrm{n}=2$; with a total of 22 participants) were used to gather detailed descriptions of participants' lived experiences (38). Semi-structured interviews allowed researchers to thoroughly explore participants' experiences of alcohol use, homelessness and use

\footnotetext{
${ }^{2}$ To define heavy alcohol use, we used criteria of the National Institute on Alcohol Abuse and Alcoholism: 1) consuming more than 4 drinks on any day or more than 14 drinks per week for men or 2) consuming more than 3 drinks on any day or more than 7 drinks per week for women (35).

${ }^{3}$ To define binge drinking, we use the criteria of the Substance Abuse and Mental Health Services Administration: 1) consuming 5 or more alcoholic drinks on the same occasion (i.e., at the same time or within a couple of hours of each other) on at least 1 day in the past month for males or 2) consuming 4 or more alcoholic drinks for females on the same occasion on at least 1 day in the past month for females (36).
} 
of or exclusion from services as well as how they envision a future WS. In the context of participatory research, community partners decided that certain topics that emerged in semistructured interviews (e.g., gender differences that marked homeless experience, use of services, police harassment and profiling, etc.) that could affect WS design and implementation needed to be further explored. Participants with similar characteristics of those who participated in the semistructured interviews were recruited for two focus groups. Focus groups also allowed eliciting collective views and disagreements among participants (39), revealing the diversity of experiences and expectations within this population. Semi-structured interviews lasting 20 to 80 minutes and focus groups lasting 75 to 100 minutes were recorded and digitally transcribed. Monetary compensation was offered to individuals who participated in semi-structured interviews and focus groups (CAN\$40).

Audio transcripts of the semi-structured interviews and focus groups were thematically analyzed with the support of NVivo 12 software. Participants' names were anonymized, and all additional identifying information was removed to protect participants' privacy. In keeping with the community-based participatory research approach of this study, preliminary analysis of the collected data was discussed in meetings with the community research partners, who provided their feedback. The collected data was reviewed again through iterative analysis (40) to identify emergent themes and sub-themes, and to refine the coding process. To ensure validity, three researchers (RMO, NIS, JFA) analyzed over $10 \%$ of the gathered data, with $95 \%$ agreement (41). To obtain consensus, researchers held face-to-face meetings during the study period. In keeping with the community-based participatory research approach of this study, the community research partners participated in several of these meetings, contributing their expertise to redefine the research process when needed.

\section{Results}

In this section, we will examine participants' backgrounds; alcohol use and homelessness experiences; their use of services and experiences of exclusion; and their vision of an ideal WS.

\section{Participants' backgrounds, alcohol use and homeless experiences}

More than half of participants were men, two fifths were women and one tenth did not identify with any binary gender/sex category. They ranged in age between 24 and 71, the mean age was 49.4 years old. Almost all of the participants were born in Canada, half in the province of Quebec; more than half spoke French as a first language. Four fifths identified as white and the rest as Indigenous (First Nations, Inuit or Métis). All participants identified as heavy alcohol users and alcohol dependent. All participants drank alcoholic beverages, and one fifth drank both alcoholic beverages and non-beverage alcohol. In addition to alcohol, the majority used other substances, the most common being cannabis, cocaine (cocaine powder and crack), amphetamines, prescription opioids and tranquilizers (benzodiazepines).

All participants identified as currently experiencing homelessness or as not having stable, safe, adequate and healthy homes (42). Most alternated living in multiple places for periods of time, including their own apartments or rooms, the streets, shelters, transitional houses, friends' apartments, and hotel rooms. Half of them reported living almost exclusively in the streets. Several had access to their own apartment or room through municipal and community programs, but participants noted their alcohol and drug use affected the ability to retain their housing. Sylvia, one of the participants, pointed out, "I often take the rent money for my consumption, so I end up on the streets." Other participants commented that certain practices associated with their substance 
use (e.g., having friends home, making too much noise, using common areas to consume substances) were sources of conflict with neighbors and landlords, and causes of housing loss.

All participants had lived on the streets during periods ranging from one month to fifteen years. They reported experiencing harsh living conditions, instability and, consequently, widespread feelings of insecurity. Most noted that the extreme cold weather in Montreal caused frostbite, hypothermia and respiratory diseases, and heightened risks of death. They also reported being targets of frequent assaults and robbery, as Armand said: "In the year and a half I've been on the streets, I've renewed seven, eight health insurance cards [because] my backpack got stolen eight times." Many felt constantly stigmatized and judged by people in public areas because of their alcohol use and/or being homeless. Of note is the intense police harassment that the participants highlighed. Montreal Police has been publically accused of social profiling ${ }^{4}$, which reflects on the participants' descriptions. They reported that police often confiscated their alcohol or forced them to "pour it out", as well as "tested" their sobriety in unlikely ways (e.g., "The cops asked me to walk in a straight line and I didn't even have a car!"). Moreover, they reported that the police constantly handed out fines for drinking or being drunk in public areas, sleeping in subway stations and traveling in the subway without paying. Many revealed that they cumulated "astronomical" debts due to their inability to pay the fines. They considered it a serious obstacle if they decided to getting off the streets and "reintegrating into society." Thus, the harsh conditions of living on the streets and associated stresses increased their substance use, as Sandra reported: "You get drunk to stay warm and then you get vulnerable because you're drunk and alone ... and then you do drugs because you don't wanna fall asleep ... it's just an endless cycle."

\section{Use of services, public policies, and exclusion}

Most participants considered that their substance use and/or experience of homelessness limited their access to several health and social services. For example, shelters in Montreal do not tipically admit people under the influence of alcohol. According to Jack: "The problem is that when you're a little drunk and you try to sleep in a shelter, [the staff] want to smell your mouth. [To get in], I have to eat a lot of gum and put on perfume!" In addition, most shelters forbid users to bring alcohol inside, which discouraged several participants from using them because of alcohol withdrawal (e.g., sweating, increased heart rate, hand tremors, agitation, seizures, etc.). Alcohol deprivation can severely compromise their health, as Mario stated: "I'm not currently eligible for shelters because in the morning I wake up and then I shake. If I don't drink, I can end up in a hospital! It's happened to me before, I had angina pectoris when I was without drink." Although all shelters have strict rules about forbidding alcohol use, some staff members had a more flexible approach and allowed participants to drink in their rooms to prevent health complications.

Almost all participants had income of less than CAN\$12,000, which is extremely low for Canadian standards of living. Most were unemployed and their main source of income was social assistance (welfare.) However, many were often excluded from welfare support for short and/or long periods of time due to internal rules regarding leaving the province. Welfare benefits are easily suspended to anyone who leaves the province of Quebec for more than 15 cumulative days in a calendar month or more than 7 consecutive days in that month (44). Moreover, as participants were frequently robbed, they did not always have identification cards to cash their welfare checks at a bank. In addition to welfare, almost all participants had street-based economic activities as

\footnotetext{
${ }^{4}$ Montreal Police's social profiling practices have been the source of public debates and have been sparked by several research reports, which have called out these practices and have proposed specific recommendations to end them (43)
} 
complementary sources of income, such as panhandling, "squeegeeing" (wiping the windshields of cars stopped in traffic in exchange for money), sex work and petty drug trade. Due to drugrelated petty crime and police tickets ${ }^{5}$, several participants were incarcerated in provincial jails and federal prisons. According to these individuals, their criminal records were among the factors that precluded them from being employed within the formal economy.

Participants had health issues commonly associated with alcohol use, including liver diseases, hypertension, and coronary heart disease. Several had chronic health conditions such as respiratory diseases and chronic pain that, as mentioned before, were provoked or exacerbated by harsh street life conditions. As residents of the province of Quebec, they were covered by the public health insurance plan to treat their health problems, but the fact that they frequently lost their identification cards limited their access to health services. They mostly used emergency departments and to do so, the police had to intervene. As Erica stated, "Lacking ID is hard, no health card, so the cops call the ambulance, and the [paramedics] have no choice to take you to the ER." According to the research participants, only one clinic in Montreal (Médecins du monde) does not require an insurance card; but those who lived far from it and could not pay for public transportation were not willing to go there, as Gabrielle said: "I live in Vaudeville ... I'm not gonna walk ... all the way with my dog just to sit for a walk-in." Moreover, some participants reported that "prejudices" associated with alcohol and drug use as well as with their homeless condition influenced how certain health providers treated them and discouraged them from seeking institutional health care. According to Max, "[The medical staff] look at you with these judgemental eyes ... Stop looking at me like that! It's not my fault I don't have anywhere to live ... I drink because I'm sick!" Additionally, some participants stated that they did not want to be hospitalized because most health providers did not consider alcoholism a "disease" and did not allow them to drink the alcohol they needed to prevent withdrawal symptoms.

Several participants reported having one or more mental health conditions, the most frequent being depression, anxiety disorder and borderline personality disorder. Most of them received psychiatric treatment that was mostly pharmacological, which costs of which were fully covered by the Province of Quebec's public drug insurance for people on social welfare (45). However, some participants reported wanting psychotherapy and not being able to access it. Publicly funded psychological services are very limited (46) and are restricted to major mental health problems, as Mathieu reports: "I want psychological help ... [but] it's restricted ... you have to be really sick ... you have to be schizophrenic or something serious like that."

An important number of participants partook in various harm reduction programs for drug users provided by the government of Quebec through community-based organizations. They participated in needle and crack equipment distribution programs, supervised injection services, opioid agonist treatments, HIV and hepatitis C prevention and testing, etc. They considered that those programs were adapted to their needs and valued them, as Marie stated: "I appreciate Incognito, [a community-based organization that send] those buses, the night buses, where you can get tested for HIV, you can get condoms, latex-free condoms, and coffee." Conversely to what they experienced in health services, they reported that the staff of community-based organizations had non-judgemental attitudes toward persons who use substances, which contributed toward creating environments in which they felt comfortable and welcomed. However, they highlighted that there were no equivalent harm reduction programs for alcohol users.

\footnotetext{
${ }^{5}$ Until 2004, the municipal court of Montreal issued warrants of imprisonment for non-payment of tickets for minor infractions (43)
} 
Until now, we have described how structural conditions such as homelessness, poverty, social stigmatization, and police harassment and profiling situate the participants in vulnerable positions, exacerbated by their alcohol dependence. Moreover, their structural vulnerability and alcohol dependence come into conflict with health and social services policies, limiting their access. During a focus group, while discussing their experiences of being rejected from shelters, Jeremey, Mathieu and Arthur described this situation as follows:

Jeremy: The minute [the staff] notice we're intoxicated, they leave us outside, they don't want the trouble of taking care of us ... they allow themselves to select those ... who are less likely to cause problems.

Mathieu: They want the good homeless!

Arthur: But they should be helping those with problems ...

Mathieu: Those who need more help!

By focusing on what the participants called "good homeless," staff members of shelters and other services excluded those who were most vulnerable and in need of such services.

\section{Envisioning Montreal's WS}

We asked participants to envisioned an ideal WS. In doing so, we wanted to tap into their experiential knowledge to design a WS tailored to the specific needs and expectations of our target population. One participant depicted it as "a place to be safe, feel at home and get better," which summarizes the expectations that most participants associated with this service. Below we describe in detail the main features that, according to the participants, a WS should have.

\section{WS as safe space to drink}

All participants considered that the WS should be a site where people could "consume alcohol safely." Several participants would like the WS to operate like a "supervised injection site," but for alcohol users. They highlighted their need for a "safe place" with "medical" staff available who could help them in case a "bad trip" or health complications arise while drinking.

Additionally, several participants suggested that it should be like a "drop-in centre" and a "shelter," open "24/7," where people can "drink alcohol indoors." Marie noted that drinking alcohol on "the streets," is "forbidden," and thus "causes a lot of trouble" and exposes participants to more "risks." Among the risks that the WS could prevent or reduce, participants listed "police harassment" and "tickets" for drinking or being intoxicated in public areas, being "assaulted" and "robbed" while drunk, as well as exposure to "cold weather" with consequences of "getting sick" and/or "dying in a snowbank." Additionally, several participants envisioned using the WS to drink safely after waking up to prevent "withdrawal." Moreover, some participants pointed out that the risks of living on the streets put them in a constant state of "alert and stress," for which a place that gives them respite could bring a sense of security and thereby have a positive impact on their mental health.

To create this safe space, several participants considered that certain "flexible rules," adapted to their lifestyles and needs was critical. For example, in contrast with most shelter policies, they wanted that in the WS users could hold their beds for "a week or so." Also, most 
would like a rule that prevents users from getting "really, really drunk" in the WS because people who "drink too much" tend to become "violent," which could be disruptive and threatening for others.

\section{WS as place for the provision of multiple services}

The limited access of the participants to health and social services strongly influenced how they envisioned an ideal WS. Many participants considered that the WS should offer temporary accommodation to alcohol users (wet shelter) who were regularly excluded from shelters and should facilitate their transition to stable forms of housing. Additionally, most considered that the WS should have medical staff not only to supervise their alcohol use, but to treat them for their chronic illnesses and transfer them to specialized medical services when needed. Furthermore, several participants highlighted that the WS should provide therapeutic services to address psychological problems they saw as closely related to their alcohol and drug use. According to Cedric, in the WS, "There should be workers like ... psychologists because a lot of us have mental health problems and to treat them, we take our 'medication' ... we drink ... instead of [getting psychological] therapy."

In addition, many participants would like to have at the WS a social worker to help them renew identification documents, to reapply for "welfare checks" when suspended, to get stable "housing," to navigate their "problems with the legal system," and to find a "job." Moreover, several considered that the WS should provide occupational training to facilitate job "reintegration" and to be itself a source of employment. In one focus group, several participants exchanged ideas about this possibility and imagined together an entrepreneurial project suitable to their interests and needs, that would increase their sense of belonging and allow them to give back to the WS:

Mathieu: I think that [the WS] could be like a social reintegration program.

Cedric: We can make our own wine ... I think it might be interesting to have a little project there for those who want to work ... It would create jobs and then in addition you would have your drink!

Mathieu: Then, it could be a form of self-financing for the centre as well ...

Max: I think ...we should have responsibilities like cleaning ...

Cedric: Volunteering, doing something, giving time ... it creates a sense of belonging ...

Oscar: Like in a monastery! [laughs]

Carl: Wine and cheese!

Cedric: A business run by homeless for ... reintegrating into society.

Finally, almost all participants highlighted the need for workers to be well "qualified" in the provision of the multiple services as well as "well-paid" to prevent constant staff turnover. They also emphasized that they did not want workers to treat them like "children," trying to 
"control" and "punish" them for breaking the rules. Instead, they would like workers to be "respectful," non-judgemental, "compassionate," "warm" and "caring." In the case of outreach workers, some felt that they should have experiences of homelessness and/or consumption to be able to "understand" the users' difficulties and challenges, and "adapt" the WS to users' needs.

\section{WS as home}

Several participants stated that, in addition to services, the WS should provide them with a sense of security and belonging that would make them feel "at home." They considered that the WS could potentially be a suitable place to "remember" or "relearn" how to do some daily living activities not used when homeless such as "cooking," "doing the laundry," "cleaning," and "making the bed". Furthermore, they pointed out that living with others at the WS would allow them to improve their "social" and "communication" skills, thus consequently feel less isolated.

Noteably, several participants considered that the WS should help them to preserve their relationships with "significant others" such as partners, friends, family members and pets. In this sense, they would like to be able to have and/or host visitors at the WS. Moreover, they pointed out that the WS should be designed as a "pet-friendly" environment because several people experiencing homelessness have animals as companions. Most shelters forbid pets, which limited the participants' access to such services, as Cedric described shelters: "It would be super cool if [the WS] took animals! I spent two winters with my dog sleeping outside because none of the shelters take animals."

Most participants considered that the WS should be designed as an inclusive environment where men, women, sexual minorities, couples, and diverse ethnic groups feel "at home." However, some women who had experienced various forms of abuse perpetrated by men pointed out they preferred that the WS be segregated by sex/gender ("one WS for women and other for men") or that the WS have private areas exclusively for women. In addition, some participants who identified as white would prefer a WS where there were no Indigenous people because in their words "Indigenous people dr[ink] too much" and/or do not "tolerate alcohol very well," and thus they turn "violent" and "f[ight] with others." Conversely, participants who identified as Indigenous considered that the WS should include people from different ethnicities and did not ask for a WS exclusively for Indidgenous people.

Several participants stated that they wanted the WS to be adapted to their cultural norms, preferences, practices and language. For example, white participants pointed out that they did not like the food many shelters provide because they felt it was "unfamiliar" and foreign. According to Renée, "[At the shelter] they gave us curry and 90\% of us were Quebecers. We didn't eat ... I wonder why they don't give us just sandwiches or something simple we like." Alternatively, participants who identify as Indigenous indicated that at the WS they would like to have Indigenous games and activities and not only "Western" board games. Furthermore, some participants wanted bilingual (English and French) workers. According to participants from outside Quebec who only speak English, in most public services they attended providers did not speak English, which discouraged them coming back.

\section{WS as site of recovery}

Most participants considered that the WS should be a site of "recovery" from alcohol use and harsh living conditions. They stated that having a safe place to drink and live would "definitely" have a positive impact on their "physical and mental health," as well as their general "wellbeing." 
Moreover, building on their own perceptions of recovery, they would like the WS to offer therapeutic resources such as "detox," "rehab," "medication," addiction "therapies," and medical "follow up" for those who want to "stop," "moderate" or reduce the harms associated to their drinking. Some suggested that the WS should host support groups such as Alcoholics Anonymous for those who want to stop drinking and stay sober.

Most participants commented that the WS should provide a form of "supervision" or "control" for those who want to moderate their drinking or reduce the associated harms. They consider that supervision should be "flexible enough" to allow users to drink without "feeling inhibited," and to respect each person's drinking pattern, but it had to prevent users from "excessive drinking" or binging. However, when we asked participants to imagine ways to monitor users' drinking, their answers were vague as Carl's response illustrates: "If there is no supervision [in the WS], it would be a mess! ... but how to do it ... for everyone ... no idea." When we explained that users could be given regulated doses of alcohol according to individualized plans (MAP), several believed that this "might work" for them. Others who considered they needed to drink "a lot" on every occasion were hesitant about the applicability of this type of monitoring. According to Marco, "I'm just a bad drunk and a wicked drunk ... I can't take just a drink because ... I can't stop!"

Despite their hesitations, participants highlighted that being surrounded by people who try to stop drinking or to drink in a controlled way would be "very inspiring," and when "ready" it would be a "motivation" to reduce their own drinking. Moreover, several participants suggested that to ensure users' recovery, the WS should "redirect" their "attention to drinking" through artistic activities ("painting," "writing," "playing music"), film screenings, as well as games and sports. Some participants also considered that to "keep" users "busy" the WS should offer a variety of basic workshops on using the Internet and digital technologies.

Of note, a few participants disagreed with the possibility of implementing a WS because it would enable and/or increase users' drinking, which would constitute an obstacle to their recovery. For example, Arleen considered that having a place that provides shelter and alcohol to users was "a terrible idea" that would "make it way too easy for homeless people," who would "keep drinking." Additionally, Sebastian pointed out that in a place where "everyone consumes, one would encourage the other" and the users would "end up" drinking more than when they were "alone."

\section{Discussion}

This article explores how a group of persons who experienced alcohol dependence and homelessness envisioned an ideal WS. Our study aims to contribute to the growing literature about WSs and MAPs that incorporates the users' perspectives to evaluate and improve harm reduction interventions for problematic alcohol use. These studies trace the effects of such interventions on users' alcohol consumption, housing retention, encounters with police, emergency department visits, physical and mental health care and quality of life $(23)(24)(25)(26)(27)(28)(29)(47)(48)$. However, only a few studies (30)(31) incorporate participants' perspectives into the design phase of these services. We considered that integrating the experiential knowledge of potential users in the design of interventions could help to develop WSs better adapted to users' expectations and needs. Moreover, it could increase the possibilities of user engagement and thus the overall reach and impact of interventions and services as other studies on the field of health care science have shown (49)(50)(51)(52). Furthermore, involving users in the development of design is asserting 
the value of their knowledge and ability to actively participate in their own care, which might contribute to their empowerment.

Our findings aim to shed light on how excluding vulnerable populations from health and social services occurs. As some studies have shown, individuals with low incomes and who experience homelessness, violence, and/or exploitation are more likely to engage in heavy drinking, exhibit extreme intoxication and drink cheap and/or non-beverage alcohol (53)(54). In addition, our study highlights that the intersection between participants' structural vulnerability, alcohol dependence and health and social services regulations produced forms of exclusion despite the fact these services are actually citizenship rights. Social and health policies that regulate access to public services as well as the practices of service providers may be influenced by ideas of deservingness that distinguish between those who are worthy and unworthy of receiving support (55)(56). This might be the case when staff members at shelters only allow access to what the participants called "good homeless" and left out those who are intoxicated and exhibit problematic behaviors, excluding those who need help the most. Moreover, as Bernie Pauly and colleagues have shown in a recent study about ethical tensions in public health systems, the ability of practitioners to disrupt stigma and discrimination is constrained by embedded patterns of exclusion that are part of the system itself (57). Thus, despite being entitled to public services, structurally vulnerable individuals who are alcohol dependent repeatedly fall through the cracks of the health and social policy safety net.

Our study aims to contribute to the provision of inclusive services that attend to the needs of marginalized people who experience alcohol dependence and homelessness. Participants reported limited access and, to a lesser degree, refusal to attend health and social services, which is consistent with the literature about WSs and MAPs (47)(58)(59)(60). This research also shows that users of WSs and MAPs find benefit in the various services and supports accessible at those facilities, such as housing and/or transition to stable housing, social services, primary care, addiction treatments, work, as well as food and meals $(25)(28)(47)(48)(58)(61)$. Along the same line, participants considered that Montreal's WS should provide the multiple health and social services they did not receive in other care settings. Thus, co-locating multiple services (mental and physical health care, addiction treatment, and social assistance), often referred to as "one-stop shopping" (62), might be an optimal way to deliver comprehensive and integrated care at Montreal's WS. However, in his study about a residential facility that combined health and social services with supervised drinking, Joshua Evans (63) warned about the paradox of inclusively caring for a population seen as undeserving of help in an enclosed location by excluding it from the rest of the city's geography ${ }^{6}$. Although initially, Montreal's WS could provide multiple services in a single site, to thoroughly foster user inclusion, it is crucial to establish collaborations and coalitions with authorities and stakeholders toward implementing policies that lower the thresholds of existing public services in the long term.

Our study results highlight the need to tailor services to the individual needs of people who experience alcohol dependence and homelessness. Far from being a uniform population, these people have a diverse range of experiences of alcohol use (e.g., those who consider that they drink a lot and binge frequently, and those who do not), substance use (e.g., those who use drugs in addition to alcohol and those who do not) and homelessness (e.g., those who mostly have unstable forms of housing and those who almost exclusively live in the streets). Their needs and expectations about WSs are also shaped by their gender (e.g., several women would like segregated

\footnotetext{
${ }^{6}$ Evans calls this a paradoxical geography of inclusive exclusion. In another article (64), the first author has further discussed how interventions and practices that aim to foster social inclusion produce exclusions.
} 
services or spaces for females) and cultural norms. Interestingly, although all the participants agreed that the WS should be a site of recovery, they have diverse ways of conceiving their own recovery. Some envision their recovery within an abstinence framework (stop drinking), others within a harm reduction framework (reduce harms associated to drinking); some as a continuum between the two frameworks (first reducing harms associated to drinking, then progressively reducing drinking and eventually stopping it), requesting services that blur the distinctions between both frameworks. Further research about local notions of recovery among alcohol users is still needed, but our findings suggest that a person-centered approach would be more pertinent than a one-size-fits-all approach for Montreal's WS to address the different needs and expectations of this population. Of note, implementing person-centered care into practice is highly demanding, particularly for health providers. For example, assessing each individual is labor intensive and requires a wide range of expertise (65). However, research in the field of addictions has shown that applying the principles of person-centered care (e.g., individualized focus on care, holistic approach, shared decision-making, and enhanced therapeutic alliance between user and service provider, etc.) is associated with greater service use and user recovery (66)(67)(68).

Certain limitations of our study should be highlighted. Due to its qualitative design, the participants' sample does not intend to be representative of all people who experience alcohol dependence and homelessness. However, our detailed description of the participants' experiences should help others appraise the transferability of our findings to similar populations. Additionally, our study is based on semi-structured interviews and focus groups; therefore, social desirability could have been induced. Nonetheless, the interviewers' non-judgmental attitudes helped to control this potential bias. We could have used other qualitative techniques such as participant observation to enhance our study results. But since the goal was to explore participants' experiences and expectations, we considered semi-structured interviews and focus groups to be the most appropriate methodological choice. Although for the participants' recruitment, we used criteria that ensured sample diversification, the semi-structured interview and focus group guides did not include specific questions to deepen our exploration of differences by age, gender and ethnicity. Information about such differences included in this paper was mostly emergent. The perspective of Indigenous potential users of the Montreal's WS needs to be further examinined.

\section{Conclusion}

This study explored how a group of persons who experience alcohol dependence and homelessness used their experiential knowledge to envision the first WS in Montreal. Drawing on their homelessness and alcohol use experiences as well as on their service use and exclusion experiences, the participants imagined a WS as a safe space to drink, a place for the provision of multiple services, a home, and a site of recovery. Our findings aim to contribute to the growing literature about harm reduction interventions that address alcohol consumption by including the experiential knowledge of potential users into the design phase of these interventions. Finally, the study highlights the value of a community-based participatory research approach and qualitative methods (semi-structure interviews and focus groups) in capturing the lived experiences of participants.

\section{List of abbreviations}

WS: Wet Service

MAP: Managed Alcohol Program 


\title{
Declarations:
}

\section{Ethics approval and consent to participate}

This study was approved by the Comité d'éthique de la recherche en dépendances, inégalités sociales et santé publique du CIUSSS Centre-Sud-de-l'Île-de-Montréal (\# DIS 1819-47). Written consent was obtained from all participants.

\section{Availability of data and materials}

The database created and analyzed for this study is not publicly available. It is based on a small sample of research participants, which threatens their confidentiality. It could be available from the corresponding author on reasonable request.

\section{Competing interests}

The authors declare not having competing interests.

\section{Funding}

This study was conducted with the support of Santé Canada - Programme sur l'usage et les dépendances aux substances - PUDS 15.

\begin{abstract}
Authors' contributions
RMO created the database with part of the collected material which she analyzed, reviewed relevant literature, and drafted the manuscript. NIS contributed to creating the database, analyzed the collected material, helped to review relevant literature, and provided feedback to early drafts of the manuscript. HP participated in data collection, discussed the collected material, and commented the final draft of the manuscript. S-AMD was co-researcher of this study, provided advice throughout the research process and commented the final draft of the manuscript. $\mathrm{CH}$ was co-researcher of this study, provided advice throughout the research process and commented the final draft of the manuscript. PBC was co-researcher of this study, provided advice throughout the research process and commented the final draft of the manuscript. JSF was co-researcher of this study, provided advice throughout the research process and commented the final draft of the manuscript. JFA designed and conceptualized this study, participated in data collection, analyzed the collected material, reviewed relevant literature, and contributed to writing the manuscript. All authors read and approved the final manuscript.
\end{abstract}

\section{Acknowledgements}

We thank the members of the research team of this study, in particular Pierre Toussaint (research coordinator) and Michel-Philippe Robitaille (research assistant). We would like to acknowledge the support of the community research partners throughout the research process. From the Groupe de travail intégration des services dans la communauté, we thank Alain Arseneault, Jason Champagne, Manuel Penafiel and Justin Meloche (CCSMTL); Jacinthe Boucher, Carlo DeAngelis, and Martine Dubuc, (SPVM); Marc-André Fortin P., Faubourg St-Laurent, and Serge Lareault (Ville de Montréal); Aubin Boudreau (Accueil Bonneau), and Sylvia Rives (Société de développement social). From the Groupe de travail sur l'organisation des services, we thank Martin Camiré, Jason Champagne, Elaine Polflit, Catherine Lessard, and Justin Meloche (CCSMTL); Serge Lareault and Geneviève Ledoux (Ville de Montréal); Matthew Pearce and Florence Portes (Old Brewery Mission); Marina Boulos (Chez Doris); David Crane (Cabot 
Square); Carlo DeAngelis (SPVM); Véronique Houle (Médecins du Monde); and Martin LaFortune (Maison 1'Exode). From the Comité de pilotage, we thank Jason Champagne, Annie Larouche, and Julie Grenier (CCSMTL); Sylvie Cornez (Société Makivik); Carlo DeAngelis (SPVM); Serge Lareault (Ville de Montréal); Annie Gauthier (arrondissement Ville-Marie); and Guillaume Legault (RAPSIM). We also thank the persons with lived experiences that provided valuable feedback at different steps of the research process. We extend our acknowledgments to our research participants without whom this study would not be possible.

\section{References Cited}

1. Griswold MG, Fullman N, Hawley C, Arian N, Zimsen SRM, Tymeson HD, et al. Alcohol use and burden for 195 countries and territories, 1990-2016: a systematic analysis for the Global Burden of Disease Study 2016. The Lancet. 2018 Sep 22;392(10152):1015-35.

2. World Health Organization. Global status report on alcohol and health 2018. World Health Organization; 2018.

3. Hannah R, Roser M. Alcohol consumption [Internet]. Our World in Data. 2018. Available from: https://ourworldindata.org/alcohol-consumption

4. McVicar D, Moschion J, van Ours JC. From substance use to homelessness or vice versa? Soc Sci Med. 2015 Jul;136-137:89-98.

5. Fazel S, Khosla V, Doll H, Geddes J. The Prevalence of Mental Disorders among the Homeless in Western Countries: Systematic Review and Meta-Regression Analysis. McGrath J, editor. PLoS Med. 2008 Dec 2;5(12):e225.

6. Fazel S, Geddes JR, Kushel M. The health of homeless people in high-income countries: descriptive epidemiology, health consequences, and clinical and policy recommendations. The Lancet. 2014 Oct;384(9953):1529-40.

7. Agardh EE, Allebeck P, Flodin P, Wennberg P, Ramstedt M, Knudsen AK, et al. Alcoholattributed disease burden in four Nordic countries between 2000 and 2017: Are the gender gaps narrowing? A comparison using the Global Burden of Disease, Injury and Risk Factor 2017 study. Drug Alcohol Rev. 2020/11/18 ed. 2021 Mar;40(3):431-42.

8. Wright NMJ, Tompkins CNE. How can health services effectively meet the health needs of homeless people? Br J Gen Pract J R Coll Gen Pract. 2006 Apr;56(525):286-93.

9. Center for Behavioral Health Statistics and Quality. Behavioral Health Trends in the United States: Results from the 2014 National Survey on Drug Use and Health (NSDUH) [Internet]. [cited 2021 Aug 30]. Available from: https://www.samhsa.gov/data/report/behavioral-health-trends-united-states-results-2014national-survey-drug-use-and-health 
10. Nilsson SF, Hjorthøj C, Erlangsen A, Nordentoft M. Suicide and unintentional injury mortality among homeless people: a Danish nationwide register-based cohort study. Eur J Public Health. 2014;24 1:50-6.

11. Fischer PJ, Breakey WR. The epidemiology of alcohol, drug, and mental disorders among homeless persons. Am Psychol. 1991;46(11):1115-28.

12. Solarz A, Mowbray C. An Examination of Physical and Mental Health Problems of the Homeless. In 1985.

13. Burak A, Cierzniakowska K, Popow A. Homeless people under the influence of alcohol admitted to hospital emergency departments in Poland. Nord Alkohol- Nark NAT. 2020;37:190-200.

14. Sandoval E, Smith S, Walter J, Schuman S-AH, Olson MP, Striefler R, et al. A Comparison of Frequent and Infrequent Visitors to an Urban Emergency Department. J Emerg Med. 2010 Feb 1;38(2):115-21.

15. Palepu A, Gadermann A, Hubley AM, Farrell S, Gogosis E, Aubry T, et al. Substance use and access to health care and addiction treatment among homeless and vulnerably housed persons in three Canadian cities. PLoS ONE. 2013;8(10).

16. Asana OO, Ayvaci ER, Pollio D, Hong B, North C. Associations of alcohol use disorder, alcohol use, housing, and service use in a homeless sample of 255 individuals followed over 2 years. Subst Abuse. 2018;39:497-504.

17. Canavan R, Barry MM, Matanov A, Barros H, Gabor E, Greacen T, et al. Service provision and barriers to care for homeless people with mental health problems across 14 European capital cities. BMC Health Serv Res. 2012 Jul 27;12(1):222.

18. Côté P-B, Renard-Robert G, MacDonald S-A. «C'est pour eux que je travaille » : étude de cas sur le pouvoir d'agir des professionnels œuvrant auprès de personnes en situation d'itinérance. Can Soc Work Rev Rev Can Serv Soc. 2020;37(1):23-42.

19. Côté P-B, MacDonald S-A, Renard-Robert G. Entre pouvoir d'agir et impuissance : regards croisés sur une équipe spécialisée en itinérance. Reflets Rev D’intervention Soc Communaut. 2020;26(1):35-58.

20. Quesada J, Hart LK, Bourgois P. Structural Vulnerability and Health: Latino Migrant Laborers in the United States. Med Anthropol. 2011 Jul;30(4):339-62.

21. Ivsins A, Pauly B, Brown M, Evans J, Gray E, Schiff R, et al. On the outside looking in: Finding a place for managed alcohol programs in the harm reduction movement. Int J Drug Policy. 2019 May;67:58-62.

22. Flores-Aranda J, Toussaint P, Camara S, Kampang E. Revue systématique sur les modalités et les effets de services de type «wet» [Internet]. 2018 [cited 2021 Aug 30]. Available 
from: https://cqdt.iud.quebec/blogue/clienteles/itinerants-public/revue-systematique-sur-lesmodalites-et-les-effets-de-services-de-type-wet

23. Podymow T, Turnbull J, Coyle D, Yetisir E, Wells G. Shelter-based managed alcohol administration to chronicallyhomeless people addicted to alcohol. CMAJ Can Med Assoc J. 2006 Jan 3;174(1):45-9.

24. Vallance K, Stockwell T, Pauly B, Chow C, Gray E, Krysowaty B, et al. Do managed alcohol programs change patterns of alcohol consumption and reduce related harm? A pilot study. Harm Reduct J. 2016 May 9;13(1):13.

25. Stockwell T, Pauly B, Chow C, Vallance K, Perkin K. Evaluation of a Managed Alcohol Program in Vancouver, BC Early Findings and Reflections on Alcohol Harm Reduction. 2013.

26. Stockwell T, Pauly B, Chow C, Erickson RA, Krysowaty B, Roemer A, et al. Does managing the consumption of people with severe alcohol dependence reduce harm? A comparison of participants in six Canadian managed alcohol programs with locally recruited controls. Drug Alcohol Rev. 2018;37:S15Y_S166.

27. Evans J, Semogas D, Smalley JG, Lohfeld L. "This place has given me a reason to care": Understanding 'managed alcohol programs' as enabling places in Canada. Health Place. 2015 May 1;33:118-24.

28. Pauly B, Gray E, Perkin K, Chow C, Vallance K, Krysowaty B, et al. Finding safety: a pilot study of managed alcohol program participants' perceptions of housing and quality of life. Harm Reduct J. 2016 May 9;13(1):15.

29. Pauly B, Brown M, Evans J, Gray E, Schiff R, Ivsins A, et al. "There is a Place": impacts of managed alcohol programs for people experiencing severe alcohol dependence and homelessness. Harm Reduct J. 2019 Dec 16;16(1):70.

30. Ezard N, Cecilio ME, Clifford B, Baldry E, Burns L, Day CA, et al. A managed alcohol program in Sydney, Australia: Acceptability, cost-savings and non-beverage alcohol use. Drug Alcohol Rev. 2018 Apr;37 Suppl 1:S184-94.

31. Parkes T, Carver H, Matheson C, Browne T, Pauly B. 'It's like a safety haven': considerations for the implementation of managed alcohol programs in Scotland. Drugs Educ Prev Policy. 2021 Jul 2;0(0):1-13.

32. Schubert M, Borkman T. Understanding the Self-Help Organization: Frameworks and Findings. In Thousand Oaks: SAGE Publications, Inc.; 2021. Available from: https://sk.sagepub.com/books/understanding-the-self-help-organization

33. Israel BA, Schulz AJ, Parker EA, Becker AB. Review of community-based research: assessing partnership approaches to improve public health. Annu Rev Public Health. 1998;19:173-202. 
34. Wallerstein N, Duran B. Community-based participatory research contributions to intervention research: the intersection of science and practice to improve health equity. Am J Public Health. 2010 Apr 1;100 Suppl 1:S40-46.

35. Drinking Levels Defined | National Institute on Alcohol Abuse and Alcoholism (NIAAA) [Internet]. [cited 2021 Aug 30]. Available from: https://www.niaaa.nih.gov/alcoholhealth/overview-alcohol-consumption/moderate-binge-drinking

36. Substance Abuse and Mental Health Services Administration. 2019 National Survey on Drug Use and Health (NSDUH): Methodological Summary and Definitions [Internet]. [cited 2021 Aug 30]. Available from: https://www.samhsa.gov/data/report/2019-methodologicalsummary-and-definitions

37. Pires AP. Échantillonnage et recherche qualitative: essai théorique et méthodologique. In: Poupart, Jean, Groulx, Lionel-H, Mayer, Robert, Deslauriers, Pierres, Laperrière, Anne, Pires, Alvaro P., editors. La recherche qualitative Enjeux épistémologiques et méthodologiques. Montreal: Gaëtan Morin; 2007. p. 113-67.

38. Denzin NK, Lincoln YS. Transforming Qualitative Research Methods: Is It a Revolution? J Contemp Ethnogr. 1995 Oct 1;24(3):349-58.

39. Ryan KE, Gandha T, Culbertson MJ, Carlson C. Focus Group Evidence: Implications for Design and Analysis. Am J Eval. 2014 Sep 1;35(3):328-45.

40. Glaser BG, Strauss AL. The Discovery of Grounded Theory: Strategies for Qualitative Research. Aldine de Gruyter; 1967. 292 p.

41. Miles MB, Huberman AM, Saldana J. Qualitative Data Analysis. Thousand Oaks: SAGE Publications, Inc.; 2014.

42. Government of Quebec. Homelessness [Internet]. [cited 2021 Aug 27]. Available from: https://www.quebec.ca/en/family-and-support-for-individuals/assistance-andsupport/homelessness

43. Bellot C, Sylvestre M-È. La judiciarisation de l'itinérance à Montréal : les dérives sécuritaires de la gestion pénale de la pauvreté [Internet]. Éditions Wilson \& Lafleur, inc.; 2021 [cited 2021 Aug 30]. Available from: https://www.erudit.org/fr/revues/rgd/2017-v47rgd03131/1040516ar/

44. Government of Quebec. Individual and Family Assistance Regulation, Chapter II: General Eligibility Requirements [Internet]. [cited 2021 Aug 27]. Available from: http://legisquebec.gouv.qc.ca/fr/showdoc/cr/A-13.1.1,\%20r.\%201/20200101?langCont=en

45. Régie de l'assurance maladie. Last-resort financial assistance [Internet]. [cited 2021 Aug 27]. Available from: https://www.ramq.gouv.qc.ca/en/citizens/last-resort-financial-assistance

46. Chodos, Howard. Expanding Access to Counselling, Psychotherapy, and Psychological Services [Internet]. Mental Health Commission of Canada; 2017. Available from: 
https://www.mentalhealthcommission.ca/English/resources/mhcc-reports/expandingaccess-counselling-psychotherapy-and-psychological-services

47. James S, Skinner H. The Shoreline Project for Street Drinkers: Designing and Running a Supported Housing Project for the "Unhousable." Soc Mark Q. 2009 Sep 1;15(3):49-66.

48. Pauly, B., Stockwell, T., Chow, C., Gray, E., Krysowaty, B., Vallance, K., et al. Towards alcohol harm reduction: Preliminary results from an evaluation of a Canadian managed alcohol program. Centre for Addictions Research of British Columbia.; 2013.

49. Bate, Paul. Bringing User Experience to Healthcare Improvement: The Concepts, Methods and Practices of Experience-Based Design. Abingdon: Radcliffe Publishing Ltd; 2008.

50. Hagen, P., Collin, P., Metcalf, A., Nicholas, M., Rahilly, K., Swainston, N. Participatory Design of evidence-based online youth mental health promotion, prevention, early intervention and treatment. [Internet]. Young and Well Cooperative Research Centre; 2012. Available from: youngandwellcrc.org.au

51. Slattery P, Saeri AK, Bragge P. Research co-design in health: a rapid overview of reviews. Health Res Policy Syst. 2020 Feb 11;18(1):17.

52. Komaroff J, Perreault M. Toutes les organisations ne sont pas égales quant au pouvoir décisionnel de leurs pairs aidants. Drogue Santé Société. 2013 Jun;12(1).

53. Larimer ME, Malone DK, Garner MD, Atkins DC, Burlingham B, Lonczak HS, et al. Health care and public service use and costs before and after provision of housing for chronically homeless persons with severe alcohol problems. JAMA. 2009 Apr 1;301(13):1349-57.

54. McCormack RP, Hoffman LF, Norman M, Goldfrank LR, Norman EM. Voices of homeless alcoholics who frequent Bellevue Hospital: a qualitative study. Ann Emerg Med. 2015 Feb;65(2):178-186.e6.

55. Bambra C, Smith KE. No longer deserving? Sickness benefit reform and the politics of (ill) health. Crit Public Health. 2010 Mar 1;20(1):71-83.

56. Petersen MB, Slothuus R, Stubager R, Togeby L. Deservingness versus values in public opinion on welfare: The automaticity of the deservingness heuristic. Eur J Polit Res. 2011;50(1):24-52.

57. Pauly B, Revai T, Marcellus L, Martin W, Easton K, MacDonald M. "The health equity curse": ethical tensions in promoting health equity. BMC Public Health. 2021 Aug 18;21(1):1567.

58. Crane MA, Warnes A. Wet Day Centres for Street Drinkers: A Research Report and Manual [Internet]. Sheffield Institute for Studies on Ageing, University of Sheffield; 2004 [cited 2021 Aug 30]. Available from: https://kclpure.kcl.ac.uk/portal/en/publications/wet-daycentres-for-street-drinkers-a-research-report-and-manual(ad44e840-29a2-44c8-a1ca7f61a790b31e).html 
59. Burlingham B, Andrasik MP, Larimer M, Marlatt GA, Spigner C. A House Is Not a Home: A Qualitative Assessment of the Life Experiences of Alcoholic Homeless Women. J Soc Work Pract Addict. 2010 May 25;10(2):158-79.

60. Hedlund K. Community Programming in Mental Health Care Planning: A Case Study at the Drinkers Lounge in Vancouver, BC [Internet]. 2019 [cited 2021 Aug 30]. Available from: https://yorkspace.library.yorku.ca/xmlui/handle/10315/36909

61. Hedlund K. Community Programming in Mental Health Care Planning: A Case Study at the Drinkers Lounge in Vancouver, BC. undefined [Internet]. 2019 [cited 2021 Aug 30]; Available from: https://www.semanticscholar.org/paper/Community-Programming-inMental-Health-Care-A-Case-Hedlund/c39ace5d1ce88b1f6b3183af7f4d19a77039f382

62. Wood S, Austin SA. Building Bridges in Bridgeport for HIV-Positive Substance Abusers. 2009 ;

63. Evans J. Supportive measures, enabling restraint: governing homeless 'street drinkers' in Hamilton, Canada. Soc Cult Geogr. 2012 Mar 1;13(2):185-200.

64. Motta-Ochoa R, Bresba P, Da Silva Castanheira J, Lai Kwan C, Shaffer S, Julien O, et al. "When I hear my language, I travel back in time and I feel at home": Intersections of culture with social inclusion and exclusion of persons with dementia and their caregivers. Transcult Psychiatry. 2021 May 6;13634615211001708.

65. Tarter RE, Kirisci L, Ridenour T, Bogen D. Application of person-centered medicine in addiction. Int J Pers Centered Med. 2012 Jun;2(2):240-9.

66. Park SE, Mosley JE, Grogan CM, Pollack HA, Humphreys K, D’Aunno T, et al. Patientcentered care's relationship with substance use disorder treatment utilization. J Subst Abuse Treat. 2020 Nov;118:108125.

67. Barrio P, Gual A. Patient-centered care interventions for the management of alcohol use disorders: a systematic review of randomized controlled trials. Patient Prefer Adherence. 2016 Sep 15;10:1823-45.

68. Davis EL, Kelly PJ, Deane FP, Baker AL, Buckingham M, Degan T, et al. The relationship between patient-centered care and outcomes in specialist drug and alcohol treatment: A systematic literature review. Subst Abuse. 2020 Apr 2;41(2):216-31. 